\title{
E-Learning Repository System for Sharing Learning Resources Among Saudi Universities
}

\author{
Ayidh Alanazi, Maysam Abbod \\ Electrical and Computer Engineering, School of Engineering and Design \\ Brunel University London \\ \{Ayidh.Alanazi,Maysam.Abbod\}@brunel.ac.uk
}

\begin{abstract}
This paper discusses the status and diversity of needs for building a centralized e-learning repository system for Saudi Universities. The study is based on surveys that were distributed to faculty members in various Saudi Universities. The purpose is to provide an analytical overview of the current needs for a unified e-learning repository system among Saudi Universities for sharing learning objects and materials. Moreover, the primary aim of the study is to give an evaluation of the needs of faculty members by gathering facts about the current demands and future adoption among Saudi Universities. To achieve this, the services needed by each part in the universities were analyzed.
\end{abstract}

Keywords: E-learning, Saudi Universities, Repositories, Unified E-Learning.

\section{Introduction}

The concept of learning objects repositories has become more prevalent in the field of teaching as the demand for e-learning applications has steadily increased. In order to meet the growing need for e-learning content and to save developers' time and efforts, learning objects repositories have been created as means of storing units of information which are used as building blocks for developing e-learning content in accordance with the requirements of a given discipline. The repositories provide various benefits such as the speed of developing content and the reduction of cost through the possibility of sharing learning objects among different e-modules.

Learning objects have existed long before e-learning itself became common. Within the traditional classroom, a teacher may utilize cardboard cutouts, maps and images to serve educational purposes. Then another teacher may choose to use some of these very objects alongside others in a different context to serve different teaching purposes. Later, the student may borrow some of these resources from a library or a learning objects centre in order to do homework assigned by the teacher. Nowadays, with the advent of the age of digital learning environments, educational designers have replaced traditional centers of learning resources with digital libraries or what was initially termed "learning resources banks". These banks store multimedia resources of information which can be used in various contexts to serves different teaching purposes [1]. 


\section{Literature Review}

Several studies have stressed the possibility of using digital learning objects repositories in developing various skills. For example, the study by Boskic at The University of British Columbia concluded that reusing learning objects already available in repositories benefits curriculum designers who can choose the objects which suit the design of their curriculums and determine the interaction level that matches the leaner's comprehension abilities [2].

Another example of the benefits can be seen in the study by Catherine Caws and Norm Friesen. Researchers at Victoria University and Alberta University in Canada designed an e-repository called (FLORE) for teaching the French Language in the post-high school stage. The repository stores 900 learning objects and allows its users to search for objects by entering the title, author, description or URL, thus providing ease of access. The study concluded that there was an increase in the learning skills for those who used the repository to learn French [3]. Furthermore, the study by Ambe-Uva aimed to evaluate the long-distance learning programs at the Open University in Nigeria. The study concluded that their open-learning students exhibited a lower quality of learning than their counterparts who relied on e-repositories [4].

Different initiatives have been implemented to streamline e-learning repositories across organizations and educational institutions, and each has a different approach [5]. The concept of UER is to offer a system that is accessed by a web portal for the purpose of managing learning contents in the repository. In such systems, system administrators first approve the method of interaction with the objects; administrators grant specific privileges to users with respect to their different roles. Therefore, instructors, course compilers and multimedia designers, on the one hand, are given the privileges of using, reusing and updating the repository's contents. On the other hand, students are often allowed only to view and interact with the course materials, drills and activities. Every UER differs in approach and policy towards learning materials. Some UER systems grant users the privilege to copy the learning materials onto their own LMS or LCMS, while other UES systems put active limits on the use of their materials to their own learning network [6].

\section{Functions of Learning Object Repositories}

Although the published studies have agreed on a definition for learning object repositories, they disagree on specifying their functions because most repositories have been built within certain organizations to fulfill their specific needs and requirements, and most streamlining efforts among these repositories have mainly focused on facilitating the transfer and exchange of learning objects. After surveying the various studies available, the following shared functions have been identified:

- Storing learning objects metadata and providing interface panels which suit the users

- The ability to search for and reproduce learning objects using the metadata.

- Linking learning objects to each other through analyzing the metadata

- Organizing learning objects according to shared characteristics.

- Linking to digital learning environments. 
- The ability to review learning objects directly through the website of the repository.

- Providing help and technical support to the users.

- Sharing and exchanging learning objects with other repositories

- Providing tools for authoring and editing learning objects.

- Creating a cooperative environment which allows content developers to interact with each other [7][8][9][10][11].

\section{Learning Object Materials}

Different studies have compared the currently available forms of repositories as well as the predicted future forms. The study by Clifford Lynch and Joan Lippincott starts by surveying the repositories which are managed by educational institutions in the USA. Then, it compares the currently available types of learning objects in these repositories with the future types which the repositories intend to produce. The study is based on an analysis of the future plans adopted by these repositories based on user feedback. However, the published studies have not agreed on recommending specific forms for learning objects since this issue is often decided by the various needs of the course designers. By reviewing the different studies in this regard, Lynch and Lippincott agreed the following types of learning objects available in repositories in university education [11][12][13][14]: (1) Text Materials, (2) Dynamic Texts, (3) Digital Images and Pictures, (4) Moving Pictures and Video, (5) Digital Audio Files, (6) Utility Files and Software, (7) Templates and (8) Open Source Files.

\section{Classifications of Learning Objects}

There have been various attempts to classify learning objects. Some classify them according to type, while others have classified them according to the delivery method such as Susan Smith Nash, who designates the following classification [15]: (1) Online Learning Objects, (2) Learning objects stored on digital optical storage disks, (3) Multiple-delivery learning objects. Although this classification seems logical and convenient, it is not the only one available. Churchill [14] classifies learning objects according to their intended function in the learning content, thus favoring the principles of educational design and function. The classification includes the following categories: (1) Presentation and Practice Objects, (2) Simulation and Information Objects, (3) Conceptual Models and contextual Representation.

\section{Statement of the Problem}

The institutions of higher education in Saudi Arabia are keen to provide the best elearning systems, thus leading to the increased use of digital repositories. These repositories facilitates the storage and redistribution of e-content from a centralized location; however, it is only the teaching staff who are capable of utilizing the full 
potential of repositories and enriching them with e-content covering all modules across the various specialties. Therefore, there must be a shift in the role of the teaching staff from merely providing expertise on academic disciplines into becoming full-fledged experts, mentors, designers and developers of e-content and its related software. E-content constitutes the cornerstone of their modules. Consequently, the opportunities and the needs of the use of digital repositories must be explored from the vantage point of the teaching staff in Saudi universities because they are essentially the developers content in these repositories.

\section{Methodology}

The methodology followed in this study is descriptive survey using a questionnaire.

Study Sample: The study sample consisted of 189 male and female lecturers in Saudi universities who were randomly chosen.

Study Tool: The researcher has prepared a questionnaire as a tool, by making use of the tools in the previous studies and by reviewing the related literature. The tool consisted of 23 paragraphs spread over two domains: the needs for e-learning materials on the repository (10 paragraphs), and the needs for services and functionality on the repository (13 paragraphs).

Validity of the Tool: The tool was presented to 7 experienced arbitrators in the domain of e-learning of university lecturers in Saudi Arabia. They were asked to define the appropriateness of the paragraphs in the tool and suggest any amendments. The amendments were made. The tool after arbitration consisted of 23 paragraphs in two domains.

Reliability of the Tool: The tool was applied to 25 lecturers in Saudi universities from outside the samples. The reliability of the tool was verified by using Cronbach's alpha formula for internal consistency.

Table 1: Reliability of internal consistency

\begin{tabular}{ll}
\hline Domain & Reliability coefficient \\
\hline The needs for e-learning materials on the repository & 0.85 \\
\hline The needs for services and functionality on the repository & 0.81 \\
\hline Total & 0.84 \\
\hline
\end{tabular}

The response to the tool was designed as per quintet grading as follows: strongly agree (5), agree (4), neutral (3), disagree (2), strongly disagree (1).

*For the purposes of this study, the researcher calculated the degree of the Lecturers, evaluation of the type of e-learning materials they would like to be available on the repository, and the type of services and functionality should the repository provide, according to the range equation, as the follows:

1. Range $=$ largest value of response alternatives - smallest value of the response alternatives $=5-1=4$.

2. Category length $=$ (range $/$ number of categories $)=4 / 3$ levels (high, moderate, low $)=1.33$. Therefore it will be: 
- Minimum limit $=1+1.33=2.33$

- Moderate limit $=2.33+1.33=3.66$

- Maximum limit= more than 3.66

Thus the weights of paragraphs become as follows: (5.00-3.67) is high, (3.66-2.34) is moderate and (2.33-1.00) is low.

\section{Results}

The results relate to answering the first question which says: "What type of e-learning materials you would like to be available on the repository?" To answer this question, the arithmetic mean, standard deviation and the ranking of the lecturers' estimates for each of the tool paragraphs. Table 2 shows that lecturers have high perceptions about the type of e-learning materials to be available on the repository, as the arithmetic mean of their estimate of the total tool is 3.95 and SD $=0.29$. Their estimates on item 7 were high. The highest estimates were related to the material in item 9 "open source materials" which ranked first with an arithmetic mean of 4.33 and SD $=0.83$. Their estimates on item 3 were moderate. The material in item 4 "templates" ranked last with an arithmetic mean of 3.54 and $\mathrm{SD}=0.92$. The results relating to answering the second question which reads: "what type of services and functionality should the repository provide?" To answer this question, the arithmetic mean, standard deviation and the ranking of the lecturers' estimates for each of the tool paragraphs.

Table 2. Mean, standard deviation and the ranking of the lecturers' estimates.

\begin{tabular}{lcccl}
\hline Items & M & SD & Rank & Importance \\
\hline 1. Electronic text & 3.88 & 0.95 & 6 & High \\
\hline 2. Graphics and pictures & 3.95 & 0.92 & 5 & High \\
\hline 3. Video & 4.29 & 0.88 & 3 & High \\
\hline 4. Templates & 3.54 & 0.92 & 10 & Moderate \\
\hline 5. Sound files & 3.85 & 0.89 & 7 & High \\
\hline 6. Flash files & 4.32 & 0.84 & 2 & High \\
\hline 7. Dynamic maps & 3.65 & 0.85 & 8 & Moderate \\
\hline 8. Quizzes & 4.08 & 0.92 & 4 & High \\
\hline 9. Open source materials & 4.33 & 0.83 & 1 & High \\
\hline 10. Past exam papers & 3.58 & 0.91 & 9 & Moderate \\
\hline Total & 3.95 & 0.29 & & High \\
\hline
\end{tabular}

Table 3 shows that lecturers have high perceptions about the type of services and functionality which the repository should provide, as the arithmetic mean of their estimate of the total tool is 4.16 with $\mathrm{SD}=0.34$. Their estimates on item 12 were high. The highest estimates were related to the service in item 6 "connect similar subject materials to benefit the teaching staff" which ranked first with an arithmetic mean of 4.48 and SD $=0.79$. Their estimates on item 8 "Teaching staff can evaluate others teaching materials" were moderate, and ranked last with an arithmetic mean of 3.63 and $\mathrm{SD}=0.92$. 
Table 3. Means, standard deviation and the ranking of the lecturers' estimates about (type of services and functionality should the repository provide).

\begin{tabular}{lcccc}
\hline \multicolumn{1}{c}{ Items } & M & SD & Rank & Importance \\
\hline Riposte the materials & 4.27 & 0.81 & 6 & High \\
\hline Classify the materials according to subject & 4.22 & 0.87 & 7 & High \\
\hline Search engine for subject, module, course & 3.96 & 0.92 & 10 & High \\
\hline External links to other repositories & 4.15 & 0.92 & 9 & High \\
\hline Security (members only) & 4.31 & 0.83 & 5 & High \\
\hline Connect similar subject materials & 4.48 & 0.79 & 1 & High \\
\hline Tag the materials so it can be recalled easily & 4.40 & 0.81 & 3 & High \\
\hline Teaching staff can evaluate others materials & 3.63 & 0.92 & 13 & Moderate \\
\hline Teaching staff can add materials to the repository & 3.79 & 0.85 & 12 & High \\
\hline Copyright marks for the downloaded materials & 4.47 & 0.78 & 2 & High \\
\hline Connection to external sources such as u-tube & 3.88 & 0.89 & 11 & High \\
\hline Video and audio files can only be live streamed & 4.19 & 0.85 & 8 & High \\
\hline Link to existing external teaching materials & 4.32 & 0.78 & 4 & High \\
\hline Total & 4.16 & 0.34 & & High \\
\hline
\end{tabular}

The results relating to answering the third question which says: Are there statistically significant differences at the level of $(\alpha \leq 0.05)$ among lecturers' perceptions due to the Faculty variable? For answering this question, the means and standard deviations of lecturers' estimates were calculated in both tools, depending on the Faculty variable, and the results were as in Table 4.

Table 4. Means and standard deviation of the lecturers' estimates for different faculties.

\begin{tabular}{lllll}
\hline Faculty variable & M1 & SD1 & M2 & SD2 \\
\hline Medicine & 3.69 & 0.32 & 3.82 & 0.44 \\
\hline Engineering & 3.93 & 0.29 & 4.18 & 0.36 \\
\hline Science & 4.01 & 0.18 & 4.20 & 0.40 \\
\hline Education & 3.96 & 0.35 & 4.24 & 0.30 \\
\hline Law & 3.99 & 0.24 & 4.27 & 0.33 \\
\hline Management & 3.98 & 0.14 & 4.15 & 0.13 \\
\hline IT & 4.03 & 0.24 & 4.16 & 0.21 \\
\hline Total & 3.95 & 0.29 & 4.16 & 0.34 \\
\hline lype
\end{tabular}

M1 ** SD1: type of e-learning materials should be available on the repository.

M2** SD2: type of services and functionality which the repository should provide

Table 4 shows that there is a difference between the means of lecturers' estimates in both tools depending on faculty variable. To detect if the differences in the means of lecturers' estimates are of statistical significance at level $(\alpha \leq 0.05)$, depending on the faculty variable, (ANOVA) test was used and the results were as in Table 5. The results show the existence of differences with statistical significance at level $(\alpha \leq$ 0.05 ) between the means of lecturers' estimates, depending on the Faculty variable in booth tools. To determine the source of the differences between the means of lecturers' estimates, depending on the Faculty variable, the researcher used multiple comparisons (Tukey HSD) method. 
Table 5. ANOVA results depending on Faculty variable differences.

\begin{tabular}{|c|c|c|c|c|c|c|}
\hline Tool & Source & $\begin{array}{l}\text { Sum of } \\
\text { Squares }\end{array}$ & $\mathrm{df}$ & $\begin{array}{l}\text { Mean } \\
\text { Square }\end{array}$ & $\mathrm{F}$ & Sig. \\
\hline \multirow{3}{*}{$\begin{array}{l}\text { Type of materials } \\
\text { available on the } \\
\text { repository }\end{array}$} & Between Groups & 1.830 & 6 & 0.305 & \multirow[t]{3}{*}{4.015} & \multirow[t]{3}{*}{$0.001^{*}$} \\
\hline & Within Groups & 13.821 & 182 & 0.076 & & \\
\hline & Total & 15.651 & 188 & & & \\
\hline \multirow{3}{*}{$\begin{array}{l}\text { Type of services and } \\
\text { functionality should } \\
\text { the repository provide }\end{array}$} & Between Groups & 2.936 & 6 & 0.489 & \multirow[t]{3}{*}{4.757} & \multirow[t]{3}{*}{$0.000 *$} \\
\hline & Within Groups & 18.724 & 182 & 0.103 & & \\
\hline & Total & 21.660 & 188 & & & \\
\hline
\end{tabular}

* Statistically Significant

The results in Table 6 shows that the source of statistical significance differences was between the means of lecturers' estimates in faculty of medicine, and between the estimates of lecturers in other faculties (Engineering, Science, Education, Law, Management, IT) in favor of estimates of lecturers in other faculties this result means that lecturers in faculty of medicine estimate their needs of type of e-learning materials and services and functionality should the repository provide less than lecturers in other faculties.

Table 6. multiple comparisons (Tukey HSD).

\begin{tabular}{|c|c|c|c|c|c|c|c|c|}
\hline$\overline{8}$ & 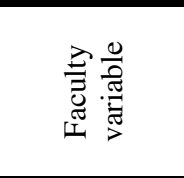 & 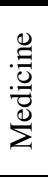 & 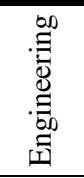 & 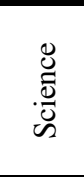 & 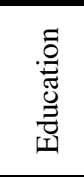 & 㣻 & 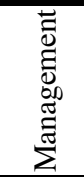 & $\Xi$ \\
\hline \multirow{7}{*}{ 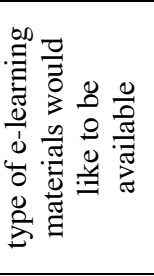 } & Medicine & - & $0.24 *$ & $0.32 *$ & $0.28 *$ & $0.31 *$ & $0.29 *$ & $0.34^{*}$ \\
\hline & Engineering & - & - & 0.08 & 0.03 & 0.06 & 0.05 & 0.10 \\
\hline & Science & - & - & - & 0.04 & 0.02 & 0.03 & 0.02 \\
\hline & Education & - & - & - & - & 0.03 & 0.02 & 0.07 \\
\hline & Law & - & - & - & - & & 0.01 & 0.04 \\
\hline & Management & - & - & - & - & - & - & 0.05 \\
\hline & IT & - & - & - & - & - & - & - \\
\hline \multirow{7}{*}{ 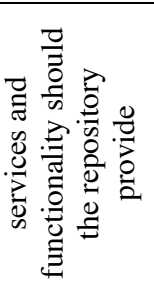 } & Medicine & - & $0.35^{*}$ & $0.38^{*}$ & $0.41 *$ & $0.44 *$ & $0.32 *$ & $0.34 *$ \\
\hline & Engineering & - & - & 0.02 & 0.06 & 0.09 & 0.03 & 0.01 \\
\hline & Science & - & - & - & 0.04 & 0.06 & 0.05 & 0.04 \\
\hline & Education & - & - & - & - & 0.03 & 0.09 & 0.08 \\
\hline & Law & - & - & - & - & - & 0.12 & 0.10 \\
\hline & Management & - & - & - & - & - & - & 0.01 \\
\hline & IT & - & - & - & - & - & - & - \\
\hline
\end{tabular}

\section{Conclusion}

The lecturers in Saudi universities have urgent needs for e-learning materials on repository. Teaching at a university level requires several materials in order to enrich 
the teaching process and provide multi-learning sources for learners such as "open source materials", "flash files", "video". However, some materials have moderate importance for teaching, like "templates", "dynamic maps" because these materials are perhaps not frequently used in teaching. Moreover, the lecturers in Saudi universities express strong needs for several types of services and functionality which the repository should provide. These include "connecting similar subject materials to benefit the teaching staff", "Tagging the materials so they can be recalled easily" and "linking to existing external teaching materials". In this regard, the function "teaching staff can evaluate others teaching materials" was not important enough perhaps because evaluating the teaching materials is not an essential part of the teaching process. Finally, it appears that the lecturers' of the faculties of medicine have less urgent needs for e-learning materials and several types of services than lecturers in other faculties. The reason may have to do with the fact that teaching medicine depends mainly on the practical application field rather than on virtual learning and elearning.

\section{References}

[1] Geissinger, H. "Re-use of current teaching resources at a dual-mode university". CampusWide Information Systems. 18.3, 120-124 (2001).

[2] Boskic, N. "Faculty assessment of the quality and reusability of learning objects". Dissirtation. Athabasca University. (2003).

[3] Caws, C., Norm F., Beaudoin, M. "A new learning object repository for language learning: Methods and possible outcomes”. Interdisciplinary Journal of E-Learning and Learning Objects. 2.1, 111-124 (2006).

[4] Ambe-Uva, Terhemba Nom. "Interactivity in Distance Education: The National Open University of Nigeria (NOUN) Experience", http://eric.ed.gov/?id=ED494376 (2006).

[5] Peters, M., Araya, D. "Networks, Information Politics and the New Paradigm of Social Production". Educational Research: Networks and Technologies. 2, 33-42 (2008).

[6] El-Saddik, A., Hossain, M. "LORNAV: Virtual Reality Tool for Navigation of Distributed Learning Objects Repositories". E-Learning Networked Environments and Architectures: A Knowledge Processing Perspective. Ed. Pierre, S. Springer Book Series, (2007).

[7] Lehman, R. "Learning Object Repositories". New Directions for Adult \& Continuing Education. 113, 57-66 (2007).

[8] MacLaren, I. "New trends in web-based learning: objects, repositories and learner engagement". European Journal of Engineering Education 29.1, 65-71 (2004).

[9] Kaczmarek, J., Landowska, A. "Model of Distributed Learning Objects Repository for a Heterogenic Internet Environment". Interactive Learning Envi. 14.1, 1-15 (2006).

[10] Griff R., McGreal, R., Hatala, M., Friesen, N. "The Evolution of Learning Object Repository Technologies: Portals for On-line Objects for Learning”. Journal of Distance Learning. 17.3, 67-79 (2002).

[11] Lynch, C. A., Lippincott, J. K. "Institutional Repository Deployment in the US as of Early 2005". D-Lib Magazine. 11.9, 1-11 (2005).

[12] Lim, C., Lee, S. and Richards C. "Developing Interactive Learning Objects for a Computing Mathematics Module". International Journal on E-Learning. 5.2, 221-244 (2006).

[13] Lee G., Su, S. "Learning Object Models and an E-Learning Service Infrastructure". International Journal of Distance Education Technologies. 4.1, 1-16 (2006).

[14] Churchill, D. "Towards a useful classification of learning objects". Educational Technology, Research and Development. 55.5, 479-497 (2007). 
[15] Nash, S. "Learning objects, learning object repositories, and learning theory: Preliminary best practices for online courses". Interdisciplinary Journal of E-Learning and Learning Objects. 1.1, 217-228 (2005). 